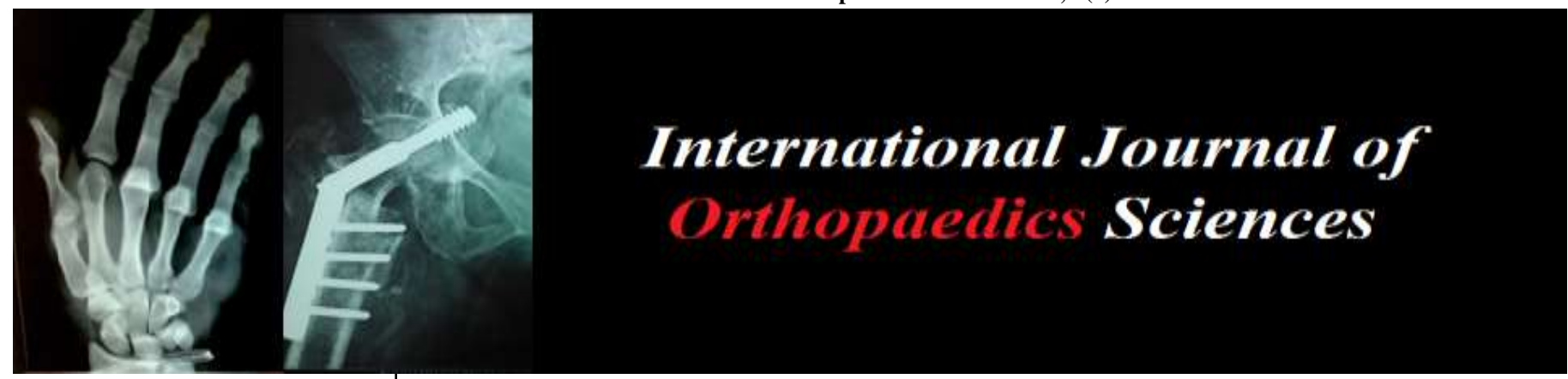

E-ISSN: 2395-1958

P-ISSN: 2706-6630

IJOS 2020; 6(4): 682-685

(C) 2020 IJOS

www.orthopaper.com

Received: 23-07-2020

Accepted: 29-08-2020

\section{Dr. E Rajaraman}

Assistant Professor, Department of Orthopaedics, Government

Medical College and Hospital,

Pudukkottai, Tamil Nadu, India

Dr. R Gokulakrishnan

Assistant Professor, Department of Orthopaedics, KAPV

Government Medical College and Hospital, Trichy, Tamil Nadu, India

\section{Dr. M Harisivanandan}

Assistant Professor, Department of Orthopaedics, Vinayaka Mission's Kirupananda Variyar Medical College and Hospitals, Salem, Tamil Nadu, India
Corresponding Author: Dr. E Rajaraman Assistant Professor, Department of Orthopaedics, Government Medical College and Hospital, Pudukkottai, Tamil Nadu, India

\section{Study of steffee fixation in spinal trauma}

\author{
Dr. E Rajaraman, Dr. R Gokulakrishnan and Dr. M Harisivanandan
}

DOI: $\underline{\text { https://doi.org/10.22271/ortho.2020.v6.i4j.2405 }}$

\section{Abstract}

Background: The management of thoraco lumbar and lumbar injuries depends on the mechanical and neurological problems due to injury of bone, ligaments, disc and cord. The steffee system of transpedicular spinal stabilization, when used with correct operative technique and a sound knowledge of the morphology of pedicles at various levels is a good, cost effective implant which can be adapted for usage in all types of thoracolumbar injuries with minimal complications.

Materials and Methods: In a prospective study conducted in the Postgraduate Department of Orthopaedics, Pudukkottai Government Medical College and Hospital, Tamilnadu over a period of 2 years. Fifty cases, both male and female in the age group of 20 to 60 years, who had undergone steffee fixation for various types of spinal injuries with neurological deficit were included. The results were analyzed according to neurological improvement as per Frankel's grading, the complications and the duration of hospital stay in both the groups.

Results: In this series $80 \%$ of patients had spinal injuries at the thoraco lumbar [D12 - L1] level. Burst Fractures and fracture dislocation were the two most common types of fractures and accounted for about $90 \%$ of the spinal injuries in this study. Out of 50 cases, 44 patients the results were good. Of the remaining 6 patients screw breakage occurred in 2 patients after the injured vertebrae had fused. Implant backing out was seen in two patients, but the $\mathrm{K}$ angle was maintained and the injured vertebrae had fused. Only in one patient the result was poor as there was screw breakage in the first month which led to loss of spinal stabilization.

Conclusion: The steffee system of transpedicular spinal stabilization, when used with correct operative technique and a sound knowledge of the morphology of pedicles at various levels is a good, cost effective implant which can be adapted for usage in all types of thoracolumbar injuries with minimal complications.

Keywords: Steffee fixation, transpedicular, thoracolumbar

\section{Introduction}

The goal of treating any injury is to restore anatomy and function of the injured part as completely as possible and to train the injured person to lead a completely normal life. It was previously considered that a case of spinal injury was a doomed case; without any protocol towards management. Early on conservative management of spinal injuries by closed reduction, immobilization and physiotherapy was practiced. Though it reduced the problems; conservative treatment modalities could not overcome the complications of spinal injuries like confinement to bed, bedsores, contractures and dependence of living. The enormous improvement in the chance of survival for paraplegic patients if the spinal column was stabilized immediately and the patient was mobilized and rehabilitated, paved way for the operative management of spinal injuries. Surgical stabilization of the spinal column in early years consisted of immobilization. Of many vertebral levels above and below the injured segment. This led to restriction of spinal column mobility. This was followed by stabilization of only segments of the spinal column. Various instrumentation systems were developed for the segmental stabilization of spinal injuries, one such was the transpedicular system of spinal stabilization started by Prof. Roy Camillee. This system underwent modifications and led to the technique of variable screw placement system developed by Dr.Steffee in 1986. A modest has been made to study the adaptability and usage of this system in injuries of the Thoracolumber region at our centre. 


\section{Materials and methods}

In this prospective clinical study, 50 patients who had undergone steffee fixation for various types of spinal injuries with neurological deficit were included. The study was conducted after receiving approval from the Institutional Human Ethics Committee. Those unwilling to participate and those unavailable during the study period were excluded from the study. The study was conducted over a period of 2 year. Clinical, functional and radiological outcomes were evaluated. Patients were in regular follow up in every month at our centre.

\section{Results}

In this study the following observations were made.

Table 1: Mode of injury

\begin{tabular}{|c|c|c|c|c|}
\hline Mode of Injury & Vehicular Accident & Fall From Height & Fall of Heavy object & Total \\
\hline No & 25 & 19 & 6 & 50 \\
\hline Percentage & $50 \%$ & $38 \%$ & $12 \%$ & $100 \%$ \\
\hline
\end{tabular}

Vehicular Accidents are the most common cause of injury, which accounts for $50 \%$.

Table 2: Injury Admission Time Interval

\begin{tabular}{|c|c|c|c|c|c|c|}
\hline No of days & 1-2 days & 3-4 days & 5-6 days & 7-8 days & 9 and above & Total \\
\hline No & 25 & 20 & 3 & 1 & 1 & 5 \\
\hline Percentage & $50 \%$ & $40 \%$ & $6 \%$ & $2 \%$ & $2 \%$ & $100 \%$ \\
\hline
\end{tabular}

Average $90 \%$ of patients being admitted in 1-4 days after injury.

Table 3: Fracture level distribution

\begin{tabular}{|c|c|c|c|c|c|c|c|c|c|}
\hline Level & D10 & D11 & D12 & L1 & L2 & L3 & L4 & L5 \& below & Total \\
\hline No & 2 & 2 & 18 & 22 & 3 & 2 & 1 & 0 & 50 \\
\hline Percentage & $4 \%$ & $4 \%$ & $36 \%$ & $44 \%$ & $6 \%$ & $4 \%$ & $2 \%$ & 0 & $100 \%$ \\
\hline
\end{tabular}

$80 \%$ of the cases fall between D12 \& L2.

Table 4: Denis Classification

\begin{tabular}{|c|c|c|}
\hline Type & Number & Percentage \\
\hline Compression Fracture & 5 & $10 \%$ \\
\hline Burst Fracture & & \\
\hline Type A & 23 & $46 \%$ \\
\hline Type B & 5 & $10 \%$ \\
\hline Type C & 1 & $2 \%$ \\
\hline Type D & - & - \\
\hline Chance Fracture & - & - \\
\hline Fracture Dislocations & 16 & $32 \%$ \\
\hline T0tal & 50 & $100 \%$ \\
\hline
\end{tabular}

According to the Dennis classification, burst fracture was more common than other type of fracture. Chance fracture did not encountered in our study.

Table 5: Pre-Operative Neurological Status

\begin{tabular}{|c|c|c|}
\hline Frankels Type & Number of cases & Percentage \\
\hline Type A & 37 & $74 \%$ \\
\hline Type B & - & - \\
\hline Type C & 2 & $4 \%$ \\
\hline Type D & 11 & $22 \%$ \\
\hline Type E & - & - \\
\hline Total & 50 & $100 \%$ \\
\hline
\end{tabular}

Recovery status was assessed by Frankel Grade.

Table 6: Associated Injuries

\begin{tabular}{|c|c|c|}
\hline Associated Injury & Number & Percentage \\
\hline Colles Fracture & 1 & $2 \%$ \\
\hline Calcaneum Fracture & 1 & $2 \%$ \\
\hline TibialCondyle Fracture & 1 & $2 \%$ \\
\hline
\end{tabular}

Table 7: Injury-Operation Time Interval in Days

\begin{tabular}{|c|c|c|}
\hline No of Days & Number of cases & Percentage \\
\hline 0-24 Hours & - & - \\
\hline 1-7 Days & 35 & $70 \%$ \\
\hline 8-14 Days & 10 & $20 \%$ \\
\hline Above 15days & 5 & $10 \%$ \\
\hline Total & 50 & $100 \%$ \\
\hline
\end{tabular}

Majority of cases recovered from $1^{\text {st }}$ week itself.
Table 8: Levels of Fixation

\begin{tabular}{|c|c|c|}
\hline Level & Number of cases & Percentage \\
\hline 2 & - & - \\
\hline 3 & 35 & $70 \%$ \\
\hline 4 & 13 & $26 \%$ \\
\hline 5 & 2 & $4 \%$ \\
\hline Total & 50 & $100 \%$ \\
\hline
\end{tabular}

3-4 Levels fixed in 96\% Patients.

Table 9: Fracture Segment Fixed / Not Fixed

\begin{tabular}{|c|c|c|}
\hline Fixed/Not Fixed & Number of cases & Percentage \\
\hline Fixed & 19 & $38 \%$ \\
\hline Not Fixed & 31 & $62 \%$ \\
\hline Total & 50 & $100 \%$ \\
\hline
\end{tabular}

Fracture segment was not fixed in 31 cases.

Table 10: Decompression C Cord Status

\begin{tabular}{|c|c|c|}
\hline Cord Status & Number of cases & Percentage \\
\hline Intact & 14 & $28 \%$ \\
\hline Contused & - & - \\
\hline Crushed & 36 & $72 \%$ \\
\hline Total & 50 & $100 \%$ \\
\hline
\end{tabular}

Table 11: Operative - Post - Operative Complication

\begin{tabular}{|c|c|c|}
\hline Per Operative & - & - \\
\hline Wound Gaping & - & - \\
\hline Infection & 2 & $4 \%$ \\
\hline
\end{tabular}

Table 12: Post-Operative Neurologist Status

\begin{tabular}{|c|c|c|}
\hline Type & Number of cases & Percentage \\
\hline Type A & 35 & $70 \%$ \\
\hline Type B & - & - \\
\hline Type C & 3 & $6 \%$ \\
\hline Type D & 12 & $24 \%$ \\
\hline Type E & - & - \\
\hline Total & 50 & $100 \%$ \\
\hline
\end{tabular}

Type $\mathrm{A} \rightarrow$ Type $\mathrm{C}=2$ Type $\mathrm{C} \rightarrow$ Type $\mathrm{D}=1$ 
Table 13: Brace - Support

\begin{tabular}{|c|c|c|}
\hline Brace & Number of cases & Percentage \\
\hline Given & 30 & $60 \%$ \\
\hline Not Given & 20 & $40 \%$ \\
\hline Total & 50 & $100 \%$ \\
\hline
\end{tabular}

Table 14: Mobilization Started in Day

\begin{tabular}{|c|c|}
\hline 1-7 Days & 1 \\
\hline 8-14 Days & 27 \\
\hline 15-21 Days & 11 \\
\hline Above 21 Days & 1 \\
\hline Total & 50 \\
\hline
\end{tabular}

Average Mobilization Time Period = Days post Op.

Table 15: Stability of Fixation

\begin{tabular}{|c|c|c|}
\hline Fixation & Stable & Unstable \\
\hline Number & 41 & 9 \\
\hline Percent & $82 \%$ & $18 \%$ \\
\hline
\end{tabular}

Table 16: Complication

\begin{tabular}{|c|c|c|}
\hline Bed Sores & 18 & $36 \%$ \\
\hline UTI & 2 & $4 \%$ \\
\hline Contractures & - & - \\
\hline
\end{tabular}

Table 17: Preoperative neurological status and follow up neurological status

In this series preoperative neurological status and follow up neurological status were as follows:

\begin{tabular}{|c|c|c|c|}
\hline Frankles Type & Pre-Op & Post -Op & Follow Up \\
\hline Type A & $74 \%$ & $70 \%$ & $66 \%$ \\
\hline Type B & - & - & - \\
\hline Type C & $4 \%$ & $6 \%$ & $6 \%$ \\
\hline Type D & $22 \%$ & $24 \%$ & $26 \%$ \\
\hline Type E & - & - & $2 \%$ \\
\hline
\end{tabular}

Type $\mathrm{A} \rightarrow$ Type $\mathrm{C}=4 \%$

Type $\mathrm{A} \rightarrow$ Type $\mathrm{C}=4 \%$

Type $\mathrm{C} \rightarrow$ Type $\mathrm{D}=2 \%$

Type $\mathrm{C} \rightarrow$ Type $\mathrm{D}=2 \%$

Type $\mathrm{C} \rightarrow$ Type $\mathrm{E}=2 \%$

Neurological recovery required an intact cord which was seen in $28 \%$ of our patients.

\section{Discussion}

In the following study in which 50 patients were operated for various types of spinal injuries at the thoraco lumbar level, all patients underwent posterior stabilization with steffee plates and pedicle screws. Spinal injuries occurred frequently in the first to fourth decade of life because these age group individuals lead an active life and are prone to injuries. In our series the percentage of patients in this age group were $82 \%$. The Male: Female ratio was 2.5:1 because the males are earning members of the Indian families and are more prone for injury. Vehicular accidents are the most common cause for injury constituting $50 \%$ of the patients studied. In a comparative study conducted by Prof-Roy-Camillee and colleagues $3 / 5$ of the patients were males and mean age for injury was 30 Years. Vehicular accidents accounted for $70 \%$ of the patients.

In our series the percentage of patients in the lower economic group was $66 \%$ showing that these people who lead an increasingly outdoor type of living are more prone for injuries. Injury admission intervals varied from 1-15 days with $90 \%$ of patients being admitted 1-4 days after the injury. An increased awareness of the importance of early treatment of spinal injuries would reduce this time interval and increase the chances for successful recovery in these patients. In this series $80 \%$ of patients had spinal injuries at the thoraco lumbar [D12 - L1] level. This concentration of spinal injuries at the thoraco lumbar junction is due to the sudden transition in the morphology of the vertebrae. In the Roy-Camillee series also the thoraco lumbar junction was the most common site for spinal injury.

Burst Fractures and fracture dislocation were the two most common types of fractures and accounted for about $90 \%$ of the spinal injuries in this study. In this series patients have been operated from the $2^{\text {nd }}$ day to 30 days after injury with a mean injury operation time interval of 3-4 days. Thus we are operating on patients within days of spinal injury. In the comparative series patients were operated within hours of injury. This delay may be due to the difficulty in mobilization of these patients to the referral centers in our set-up.

In our series all patients were operated in the prone position under hypotensive general anesthesia. Posterior decompression in the form of minimal laminectomy was done in all patients and stabilization was done using steffee plates and transpedicular screws. The mean operative time period was 2 hours \pm 15 minutes; Requiring on an average 2 units of blood transfusion. $96 \%$ of the patients had a 3-4 level fixation and the fractured vertebrae was instrumented in $38 \%$ of the patients. Per operative complications were Zero percent.; post-operatively $4 \%$ of patients developed infection of which $2 \%$ recovered and $2 \%$ required implant removal at a later stage. In the Roy - Camillee series the infection rate was $4.8 \%$ without any other per-operative or post- operative complications.

The fixation was considered stable in $82 \%$ of the patients and was unstable in $18 \%$ of the patients; which was due to faulty technique which resulted in screws being inserted outside the pedicle. Brace support was given to $60 \%$ of patients. Mobilization was started from the 12-14 post-operative day in the form of tilt table wheel chair activity and gait training. All our patients were instructed on intermittent selfcatheterization, bowel care, wheel chair activity, transfer activity and occupational training before discharge.

$36 \%$ patients developed superficial grade I to grade II pressure sores which required daily saline dressing. This was due to the delay in operation and early mobilization. The average hospital stay period for surgical procedure and rehabilitation programme was 6-8 weeks. All patients were discharged with advice on regular follow-up. The follow -up periods varied from 4 months with an average follow-up period of eight months.

In radiological assessment the $\mathrm{K}$ angle was maintained within $3^{\circ}$ of variation in $94 \%$ of the patients. Screw breakage was noted in $6 \%$ of patients which $4 \%$ occurred after the spine had fused. Implant backing out was seen in $6 \%$ of patients which $4 \%$ did not have any extreme loss of $\mathrm{K}$ angle. Plate bending occurred in $2 \%$ of the patients.

In follow up screw impingement was the major implant associated complication seen in $32 \%$ of the patients. Bladder and Bowel had recovered in $28 \%$ of the patients and was managed by self assistance in $72 \%$ of the patients. None of them required indwelling catheters. Bed sores had healed in $28 \%$ of the patients of which $12 \%$ required STG coverage. Superficial bed sores were seen in $6 \%$ of the patients and $2 \%$ had infected bedsores.

$28 \%$ of the patients in this series returned to an independent and active life; $72 \%$ led a wheel chair life, none of the patients were bed ridden. Sexually active life was led by $24 \%$ of the patients. Occupational rehabilitation and counselling 
helped $18 \%$ of the patients to do their previous occupation, $10 \%$ altered their occupation and $12 \%$ began an alternative way of living. $60 \%$ of the patients led a life dependent on others earnings.

The most common spine related second surgery was implant removal which was done in $28 \%$ of our patients. The main reason being screw impingement at the operative site. $4 \%$ of the patients required implant removal for infection and $2 \%$ for complete backing out of implant.

In this series excellent to good results were seen in $88 \%$ of the patients. With fair results in $10 \%$ and poor results in $2 \%$ these were mainly due to a fallacy in the technique of pedicle screw instrumentation and not due to any implant associated complication.

\section{Conclusion}

In this study 50 patients had spinal column stabilization at various levels using the steffee transpedicular system of fixation. In 44 patients the results were good. Of the remaining 6 patients screw breakage occurred in 2 patients after the injured vertebrae had fused. Implant backing out was seen in two patients but the $\mathrm{K}$ angle was maintained and the injured vertebrae had fused. Plate bending was seen in one patient because there was cut through of pedicle screw. Only in one patient the result was poor as there was screw breakage in the first month which led to loss of spinal stabilization. The management of thoraco lumbar and lumbar injuries depends on the mechanical and neurological problems due to injury of bone, ligaments, disc and cord. IN the case of surgical treatment these injuries can be stabilized by a posterior approach, reduction of the fracture, decompression of the cord and stabilization by the pedicle screws and plates.

The steffee system of transpedicular spinal stabilization, when used with correct operative technique and a sound knowledge of the morphology of pedicles at various levels is a good, cost effective implant which can be adapted for usage in all types of thoracolumbar injuries with minimal complications.

Even if we do not observe any recovery in case of complete neurological deficit, Reduction of displacement and good quality stabilization are necessary for optimal recovery of these patients and avoidance of a bed ridden paraplegic life.

\section{References}

1. Grays Anatomy. 37 Edition, Anatomy of Axial Skeleton and spinal cord.

2. Frank Netter H. Atlas of orthopaedic Anatomy.

3. Sir. Stanley Robbins L. Robbins Pathologic Basis of Disease.

4. Rockwood \& Green $4^{\text {th }}$ edition, Fracture and Dislocations of thoracolumbar spine Ch-23.

5. Marvin Leventhal R. Fracture, Dislocations \& Fracture Dislocations of Thoracolumbar Spine. Campbells operative ortho, 5,80 .

6. George M. Bedrook, Injuries of the spine. Watson \& Jones, $6^{\text {th }}$ edition, 2, 26.

7. George M. Bedrook, Injuries of the spine with paralysis complete or incomplete, Watson \& Jones, $6^{\text {th }}$ edition, 2, 27.

8. Michael Bracken B. Study of methylprednisolone administration and its effects in treatment of acute spinal cord injury. JAMA 1997;28(227):20.

9. Brooks ME, Aohey. Conservative versus surgical treatment of the cervical and Thoracolumbar Spine in spinal trauma.

10. Robert Bucholz W, Kevin Gill. Classification of Injuries to the Thoracolumbar Spine, Ortho. Clin. North. America 1986; $17: 1$

11. Stanley Geitzbein D. FRCS, Flexion - Distraction Injuries of the lumbar spine. Mechanism of Injury and Classfication., Clin Orhto. Rel. Research 227, 1988.

12. Fredrick Maynard M. International standard for neurological and functional classification of spinal cord injury.

13. Waters RL, Adkins RH, Yakina JS. Definition of complete spinal cord injury. Paraplegia 1991;29:573-581.

14. John Harris H. Radiological evaluation of spinal trauma, Ortho. Clin. North America 1986;17:1.

15. Ron Ferguson L, Ben Allen L. An algorithm for the treatment of unstable thoracolumbar fractures. Ortho. Clin. North America 1986;17:1.

16. Dickson RA, Chm MA. FRCS, Spinal Injuries: early surgical treatment Paraplegia 1992;30:43-45.

17. Michael Zindrick R. Analysis of the morphometric characteristic of thoracic and lumbar pedicles. Spine 1987;12:2.

18. Arthur Steffee D. Transpedicular fixation of spinal disorders with steffee plates. Surgical rounds for orthopaedics, 1987.

19. Sahu SC, Goyal RK, Gupta AK. Transpedicular steffe plate fixation in thoracolumbar spine injuries. Indian Journal of orthopaedics 1995;29:1.

20. Sven Oleurd, Govan Karlotram. Transpedicular fixation of thoracolumbar vertebral Fractures., Clin. Ortho. Rel. Research No.227, 1988.

21. Arthur Steffee D. Segment Spine Plates with pedicle screw fixation. Clin. Ortho. Rel. Research No. 203, 1986.

22. Prof. Arthur Steffee D. Variable screw placement system for spinal stabilization. Personal communication.

23. Prof. Arthur Steffee D. VSP system with posterior lumbar interbody fusion. Lumbar interbody fusion principles and techniques in spine surgery.

24. Roy R, Camillee M, Sailant DG. Plating of thoracic, thoracolumbar and lumbar injuries with pedicle screws and Plates.

25. Dr. Narayan Yoganandan. Biomechanics of lumbar pedicle screw/plate fixation in spinal trauma. Spine 1990;27:6.

26. Thomas S. White cloud Roentgen graphic measurement of pedicle screw Penetration. Clin. Ortho. Rel. Research 1989, 245.

27. AEBI M. The internal skeletal fixation system. Clin. Ortho. Rel. Research No.227 Feb, 1988.

28. Dr. Richard B. Adman, Mechanicl testing of spinal instrumentation. Clin. Ortho. Rel Research No.227, 1989.

29. James M. Geiger MS. Nancy, Bending and fatigue of spine plates and rods and fatigue of pedicle screws. American Academy of orthopaedic surgeons. Exhibit study.

30. Edward Bieber. Spinal cord monitoring during posterior spinal instrumentation and fusion. Clin. Ortho. Rel. Research No.229, 1988.

31. Caroline Mc Cagg. Post operative management and acute Rehabilitation of patients with spinal cord injuries.

32. Alan Levine M, Charles Edwards C. Complications in the treatment of acute spinal inury. Ortho Clin of North America 1986;17:1

33. Darrell Shea J. Preassure sores. Classification and management.

34. Operative Techniques in spime instrumentation. Ao Manual of internal fixation $3^{\text {rd }}$ edition. 